\title{
Feline Glucose-6-phosphate Dehydrogenase Cellular Mosaicism Application to the Study of Retrovirus-induced Pure Red Cell Aplasia
}

\author{
Janis L. Abkowitz, Richard L. Ott, Jeffrey M. Nakamura, Laura Steinmann, Philip J. Fialkow, and John W. Adamson \\ Divisions of Hematology and Medical Genetics, Department of Medicine, University of Washington, Seattle, Washington 98195; \\ School of Veterinary Medicine, Washington State University, Pullman, Washington 99164
}

\begin{abstract}
Neoplasms result from the uncontrolled clonal proliferation of abnormal or transformed cells. The early stages of this process are difficult to study because of the lack of sensitive and specific markers of clonal evolution in an experimental system. We have developed a cat model using cellular mosaicism for glucose-6-phosphate dehydrogenase (G-6-PD). Our findings confirm that the structural locus for feline G-6-PD is on the $\mathrm{X}$-chromosome and demonstrate that it is randomly inactivated in somatic cells. Heterozygous cats have balanced ratios of G-6-PD enzyme types in peripheral blood cells and hematopoietic progenitors that remain stable over time. In our initial studies, we used the model to analyze the events surrounding marrow failure experimentally induced by selected strains of feline leukemia virus (FeLV). Two G-6-PD heterozygous cats, one $F_{1}$ male hybrid and one domestic cat were infected with FeLV (C or KT) and developed pure red cell aplasia (PRCA). Colonies arising from the more mature erythroid colony-forming cell were not detected in marrow culture of anemic animals although erythroid bursts persisted, suggesting that the differentiation of early erythroid progenitors (BFU-E) was inhibited in vivo. The ratio of G-6-PD types in hematopoietic progenitors and peripheral blood cells from the heterozygous cats did not change when the animals developed PRCA. Thus, the anemia did not result from the clonal expansion of a transformed myeloid stem cell. With this experimental approach, one may prospectively assess clonal evolution and cellular interactions in other FeLV-induced diseases.
\end{abstract}

\section{Introduction}

Environmental toxins, drugs, radiation, and viruses have been implicated in the pathogenesis of human malignancy. Although the precise cellular and molecular events that result in the growth advantage of a transformed cell are unknown, host factors may influence the ability of such cells to proliferate in vivo. At the time of clinical presentation and study, most human neoplasms are derived from a single clone (1). It has

Part of this study was presented at the XI Symposium of the International Association for Comparative Research on Leukemia and Related Diseases (IACRCRD), Cambridge, England, 1983, and was published in abstract form in Leukemia Rev. Int., 1983. 1:57-58.

Dr. Abkowitz is a Special Fellow of the Leukemia Society of America. Address all correspondence to Dr. Abkowitz, University of Washington.

Received for publication 26 June 1984 and in revised form 27 August 1984

J. Clin. Invest.

(c) The American Society for Clinical Investigation, Inc.

$0021-9738 / 85 / 01 / 0133 / 08 \quad \$ 1.00$

Volume 75 , January $1985,133-140$ therefore been impossible to assess the cellular interactions that permitted the neoplastic clone to expand and dominate. For these reasons, we have developed a model of glucose-6phosphate dehydrogenase (G-6-PD) ${ }^{\prime}$ cellular mosaicism in cats to study over time clonal evolution in hematologic diseases experimentally induced by feline leukemia virus (FeLV).

FeLV is a horizontally transmitted retrovirus that, in the natural setting, causes a spectrum of hematologic disease in cats: lymphosarcoma with mediastinal mass, acute lymphocytic leukemia, myeloid leukemia, erythroleukemia, nonregenerative anemia including pure red cell aplasia (PRCA), and preleukemic myelodysplastic syndromes (2-4). As these disorders clinically resemble hematologic malignancy in man, the study of FeLVinduced diseases may be relevant to understanding human oncogenesis.

The enzymes of G-6-PD are useful markers of neoplastic growth and differentiation since they occur naturally and are independent of viral infection and cell transformation. Early in embryogenesis, that portion of one X-chromosome that contains the structural locus for G-6-PD is randomly inactivated in somatic cells of females. Once inactivation occurs, the process is fixed and a single parental G-6-PD allele remains active in each cell and all its progeny. Therefore, women heteroxygous for the usual G-6-PD gene $\left(G d^{\mathrm{B}}\right)$ and a variant (such as $G d^{\mathrm{A}}$ ) have some cells that synthesize type B enzyme, while others make type A. No somatic cell makes both G-6PD types. All tumor cells in a neoplasm originating from a single cell in a G-6-PD heterozygote will have the same single enzyme type, whereas processes arising in multiple cells and normal tissue will have both enzyme types (1).

Cellular mosaicism for G-6-PD has been used extensively to study the clonal nature and level of progenitor involvement of hematologic neoplasms in man. Such studies have shown that the chronic myeloproliferative diseases result from the clonal expansion of a myeloid stem cell common to granulocytic, erythroid, and megakaryocytic differentiation (5). Similar data have demonstrated the clonal and stem cell origin of cases of acquired refractory sideroblastic anemia (6), acute nonlymphocytic leukemia (7), and aplastic anemia (8).

Although G-6-PD has been useful in the study of human disease, information regarding cellular mosaicism in animals is relatively sparse. A variant allele at the $\mathrm{X}$-linked phosphoglycerate kinase (PGK) locus was found in feral mice and has

1. Abbreviations used in this paper: Con A, concanavalin A; ELISA, enzyme-linked immunosorbent assay; BFU-E, erythrocyte burst-forming units; CFU-E, erythrocyte colony-forming units; Ep, erythropoietin; FeLV, feline leukemia virus; ffu, focus-forming unit; G-6-PD, glucose6-phosphate dehydrogenase; MTT, glucose-6-phosphate,3-(4,5-dimethylthiazol-2-yl)-2,5-diphenyltetrazolium bromide; CFU-GM, granulocyte/macrophage colony-forming units; GM, granulocyte macrophage derived; HBSS, Hanks' balanced salt solution; PGK, phosphoglycerate kinase; PRCA, pure red cell aplasia. 
been bred into several strains (9). Clonal evolution of lymphoma has been demonstrated in these animals $(10,11)$. Whether the assay to detect PGK is sufficiently sensitive to analyze small numbers of cells (e.g., hematopoietic colonies) has not been reported. G-6-PD heterozygosity exists in the hare, but there is no established model of hematologic malignancy in this system $(12,13)$. We have found that domestic cats (Felis catus) and Geoffroy cats (Leopardus geoffroyi) have electrophoretically distinct G-6-PD types. These cats will interbreed (14) to produce female offspring that are obligate G-6-PD heterozygotes. The results of our studies of $F_{1}$ females confirm previous reports that the structural locus for feline G-6-PD is on the $X$-chromosome (15). The G-6-PD enzyme type $d$ (domestic) or $\mathrm{G}$ (Geoffroy) can be reliably assigned not only to tissues and circulating blood cells, but also to hematopoietic colonies growing in culture. In peripheral blood cells, hematopoietic precursors, and other somatic cells tested, the ratios of $d / G$ G-6-PD activities in normal $F_{1}$ females are balanced and stable. One may therefore infect cats with FeLV and prospectively assess potential clonal evolution and cellular interaction as hematologic disease develops. Because PRCA can be induced by a biologically cloned strain of FeLV (FeLV-C/Sarma) and has a short latency period $(16,17)$, we chose to study this disease as the initial application of our feline model of G-6PD cellular mosaicism.

\section{Methods}

Breeding of G-6-PD heterozygous cats. Breeding animals are housed at the School of Veterinary Medicine at Washington State University. A Geoffroy male was bred with naturally cycling domestic females with which he had previously been imprinted. Proesterus in the domestic females was determined by vaginal smear. Pregnancy was confirmed by ultrasound. Delivery was achieved vaginally or by cesarian section following a 63-66-d gestation. When weaned, female kittens were transported to the University of Washington for study.

Obtaining specimens for analysis. After animals were anesthetized with ketamine, marrow cells were aspirated from the femur or humerus into heparinized syringes. Blood samples were obtained by venipuncture.

Heparinized blood was centrifuged at $200 \mathrm{~g}$ for $10 \mathrm{~min}$ at room temperature. The top one-half of the plasma was removed and platelets were centrifuged $(8,000 \mathrm{~g}$ for $2 \mathrm{~min})$ from this fraction. To separate mononuclear cells, the remaining blood sample was diluted 1:1 with Hanks' balanced salt solution (HBSS; Gibco Laboratories, Grand Island, NY), layered over Percoll (density 1:070 g/ml; Pharmacia Fine Chemicals, Piscataway, NJ), centrifuged at $400 \mathrm{~g}$ for $20 \mathrm{~min}$, and interface cells were collected. A discontinuous density gradient (18) was used in earlier experiments and demonstrated that the best separation of feline granulocytes and monocytes was obtained with a Percoll density of 1.070. To further purify the lymphocyte preparation, mononuclear cells were placed at a concentration of $10^{6} / \mathrm{ml}$ in alpha medium (Flow Laboratories, McLean, VA) with $10 \%$ fetal calf serum (FCS; Reheis Chemical Co., Scottsdale, AZ), with and without concanavalin A (Con A; $25 \mu \mathrm{g} / \mathrm{ml}$; Pharmacia Fine Chemicals). After a 3-d incubation at $37^{\circ} \mathrm{C}$, most monocytes adhered to the plastic flask and residual neutrophils died. $95-100 \%$ of the cells appeared to be lymphocytes by Wright-Giemsa and $<5 \%$ to be monocytes by nonspecific esterase stains. Putative $T$ lymphocytes were further isolated using rat erythrocytes (19). Preliminary experiments showed that rat and guinea pig erythrocytes were equally effective in E-rosetting cat peripheral blood cells (30-40\% ER+), whereas mouse and sheep erythrocytes were less effective. Rat erythrocytes were collected in Alsever's solution (Gibco Laboratories) and washed three times in alpha medium. A suspension of $10^{8} / \mathrm{ml}$ rat erythrocytes was mixed in a 1:1 ratio (vol:vol) with $10^{6} / \mathrm{ml}$ cat mononuclear cells. The mixture was incubated for 15 min at $37^{\circ} \mathrm{C}$ in a water bath, then $1 \mathrm{~h}$ at $4^{\circ} \mathrm{C}$ and the cells were then resuspended in alpha medium. The suspended rosettes were separated from nonrosetting mononuclear cells by passage through a FicollHypaque (Litton Bionetics, Kensington, MD) density gradient (1.077 $\mathrm{g} / \mathrm{ml}$ ). Erythrocytes were lysed with Tris-HCl hemolytic buffer (Sigma Chemical Co., St. Louis, MO) and the remaining cells washed twice in alpha medium. However, cat monocytes were also rosetted by xenogenic erythrocytes, limiting the effectiveness of this technique.

Cells that migrated through the initial Percoll layer were separated into erythrocyte and granulocyte fractions with flotation in a $3 \%$ dextran solution for $30 \mathrm{~min}$. Erythrocytes were lysed from the granulocyte, platelet, and lymphocyte preparations. The samples were then frozen as pellets and stored at $-70^{\circ} \mathrm{C}$ for subsequent G-6-PD determination.

When cats died, postmortem samples of nodes, spleen, liver, skeletal muscle, and gastrointestinal tract were obtained. Part of each tissue sample was processed for histologic examination. Adjacent sections were minced and then frozen at $-70^{\circ} \mathrm{C}$ for G-6-PD determination. Mononuclear cells were also isolated from cell suspensions of spleen and nodes.

Colony assay techniques. Heparinized marrow was placed in HBSS containing 5\% FCS. Mononuclear cells, obtained as described above, were washed three times with HBSS with 5\% FCS. Cultures were established with $10^{5}$ cells suspended in alpha medium containing final concentrations of $1.2 \%$ methylcellulose (Fischer Scientific Co., Fairlawn, $\mathrm{NJ}$ ), $1 \%$ bovine serum albumin (BSA; Reheis Chemical Co), $10^{-4} \mathrm{M}$ beta mercaptoethanol, pencillin/streptomycin, and 30\% FCS, which optimized feline progenitor growth and colony morphology. Partially purified human urinary erythropoietin $(\mathrm{Ep})^{2}$ was added to the cultures; no conditioned medium was used. Cultures were incubated at $37^{\circ} \mathrm{C}$ in a high humidity, $96 \%$ air $/ 4 \% \mathrm{CO}_{2}$ atmosphere.

Erythroid colonies (from CFU-E), containing 8-50 hemoglobinized cells, were counted on day 3 or 4 of culture. Erythroid bursts (from BFU-E), containing $\geq 200$ hemoglobinized cells, and granulocyte/ macrophage (GM) colonies (from CFU-GM), containing $\geq 50$ cells, were enumerated on day 9 or 10 on the same plates as erythroid colonies.

Determination of G-6-PD activity. Cell lysates were prepared by freezing and thawing separated blood samples. Cellular debris was sedimented with centrifugation. $3 \mu \mathrm{l}$ of lysate that had been prepared from a standardized number of cells $\left(5 \times 10^{4}\right)$ or by spectrophotometric assay for G-6-PD $\left(7.8 \times 10^{-4}\right.$ dehydrogenase units), were placed on a filter paper wick (no. 1, Whatman, Inc., Clifton, NJ) near the cathode end of a polyacrylamide gel $(100 \mathrm{ml} \times 125 \mathrm{~mm} \times 0.8 \mathrm{~mm})$. The photopolymerized gel contained pH 3-10 ampholytes (Biolyte 3/10; Bio-Rad Laboratories, Richmond, CA). It was subjected to electrophoretic focusing with constant power $(3 \mathrm{~W})$ for $2.5 \mathrm{~h}$ at $4^{\circ} \mathrm{C}$ (LKB Instruments, Gaithersburg, MD). It was then incubated for 20 min at $37^{\circ} \mathrm{C}$ with a solution containing NADP, glucose-6-phosphate, 3-(4,5dimethylthiazol-2-yl)-2,5-diphenyltetrazolium bromide (MTT) and phenazine methosulfate in Tris- $\mathrm{HCl}$ buffer (pH 8.0) (20) to visualize the G-6-PD activity. The relative intensities of the single domestic G6-PD band and the minor Geoffroy G-6-PD bands (Fig. 1) were estimated visually by comparison with a standard mix of domestic and Geoffroy preparations. Since hemoglobin comigrated with feline G-6PD on cellulose acetate at alkaline pH, the amount of G-6-PD activity in nonerythroid cell lysates was confirmed by cellulose acetate electrophoresis. This electrophoresis technique was identical to that reported for the determination of human G-6-PD (20), except that NADP was omitted from the feline lysate.

To analyze tissue specimens, $20 \mu \mathrm{l}$ of distilled water were added to the stored samples. After refreezing and thawing, specimens were processed as described above.

For G-6-PD analysis of hematopoietic progenitors, colonies were

2. Ep was obtained from urine pooled from a patient with PRCA and processed in our laboratory. The partial purification procedure included ion exchange and affinity chromatography, and yielded a specific activity of $200 \mathrm{U} / \mathrm{mg}$. 


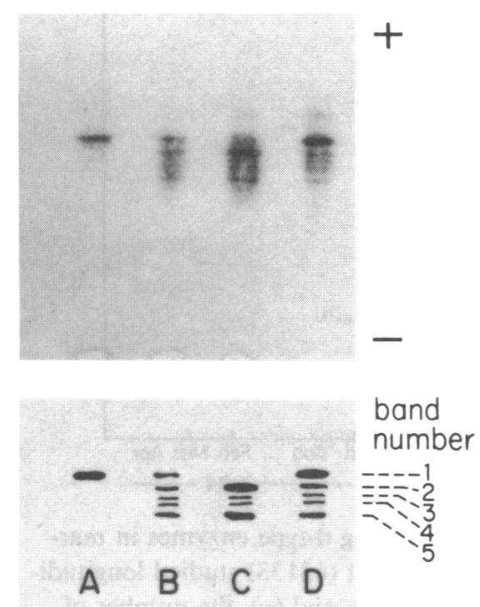

Figure 1. Isoelectric focusing of feline G-6-PD. A, domestic. B, a 1:1 mix of equal numbers of domestic (d) and Geoffroy (G) cells. C, Geoffroy. D, female heterozygote. The samples, lysates containing a total of 5 $\times 10^{4}$ granulocytes, were placed near the cathode of the polyacrylamide gel. After isoelectric focusing for $2.5 \mathrm{~h}$, the gel was stained for G-6-PD activity. A single band (1) characterized the domestic pattern. The Geoffroy has four bands, with 2 and 5 most promi-

nent. The heterozygote in this sample would be read as 70:30, d:G. The percent of Geoffroy activity is best estimated by band 5 , which never overlaps the domestic range. More accurate estimations of activity ratios are obtained with cellulose acetate electrophoresis as only one domestic and one Geoffroy band are visible with that technique.

individually harvested by micropipette under direct vision with an inverted microscope. The cells of the colonies were lysed by freezing and thawing before each sample was placed directly on a thin-layer polyacrylamide gel for isoelectric focusing.

Virus preparation. FeLV-KT, containing A, B, and C viral subgroups (21, 22), was obtained from Dr. Edward Hoover, Colorado State University, Fort Collins, CO. The virus was initially derived from FL74, a lymphosarcoma cell line, and has been repeatedly passed in vivo. A $20 \%$ weight-to-volume suspension in alpha medium was prepared from homogenized splenic tissue of an infected animal and was stored at $-70^{\circ} \mathrm{C}$.

Feline embryonic fibroblasts that were infected with biologically cloned FeLV-C/Sarma were obtained from Dr. David Onions and Dr. Os Jarrett, University of Glasgow, Scotland, and have been maintained in our laboratory. Cells were grown in McCoy's medium (Gibco Laboratories) with $15 \%$ FCS. At the time of virus harvest, a small quantity of medium was incubated for $24 \mathrm{~h}$ with fibroblasts grown to near-confluence. Aliquots of virus-rich supernatant were frozen for later use. The amount of virus in the specimens was quantitated by Dr. Edward Hoover using the $8 \mathrm{C}$ cell line focus-forming unit (ffu) assay described (23).

FeLV infection protocol. Cats received $5 \mathrm{mg}$ methylprednisolone/ $\mathrm{kg}$ subcutaneously on days $-4,0,1,4,7$, and 10 , or $10 \mathrm{mg} / \mathrm{kg}$ on days 0 and 7. FeLV was given on days 0 and 1 . Various dose schedules were used empirically to determine the optimal procedure to produce PRCA in these hybrid animals. Disease was induced most reliably with a total dose of $0.5-1.0 \times 10^{5} \mathrm{ffu} / \mathrm{kg}$. As cats became anemic they were transfused with $50 \mathrm{ml}$ of littermate blood when clinically indicated.

Before infection, peripheral blood and marrow were obtained on two occasions for complete blood count, reticulocyte count, leukocyte differential, quantitation of progenitors in methylcellulose culture, and G-6-PD analysis of erythrocytes, platelets, granulocytes, lymphocytes, erythroid bursts and GM colonies. Marrow morphology was assessed by Wright-Giemsa stain of marrow cells aspirated in EDTA. Similar studies were conducted at 1-3-wk intervals.

Viremia was detected by an enzyme-linked immunoabsorbent assay (ELISA) (Pittman-Moore \& Co., Washington Crossing, NJ), which assays gag-related antigens or by immunofluorescence staining of peripheral blood cells (24). Heterologous goat antiserum to gag (predominantly p27)-related antigens, provided by Dr. Edward Hoover, and fluorescein-labeled anti-goat immunoglobulin (Biological Carcinogenesis Branch, NCI, Bethesda, MD) were used in the indirect immunofluorescence assay.

\section{Results}

Characterization of feline hematopoietic progenitors. Marrow cells from 22 hybrid cats were cultured in vitro for progenitor cell growth. The morphology of feline erythroid colonies, erythroid bursts, and GM colonies was comparable to that described (17). Dose-response curves with Ep showed a plateau growth of erythroid colonies and bursts at 0.1 and $0.3 \mathrm{U} / \mathrm{ml}$, respectively. Normal values for the various progenitors per $10^{5}$ mononuclear marrow cells were: erythroid colonies: $202 \pm 102$ (SD); erythroid bursts: $40 \pm 21$; GM colonies: $57 \pm 18(n=51)$.

Sensitivity of the G-6-PD assay. Domestic (d) cat G-6-PD migrated as a single band on isoelectric focusing to $\mathrm{pH}$ 6.7. Geoffroy (G) G-6-PD formed several bands with more basic isoelectric points (Fig. 1). With cellulose acetate electrophoresis, one $d$ (fast) and one $G$ (slow) band were visible (data not shown). Varying ratios of $d$ and $G$ erythrocytes and granulocytes were assayed for G-6-PD activity to determine the lower limit of detection of one G-6-PD type in a mixture of the two. With isoelectric focusing, one could detect as little as $5 \% \mathrm{~d}$ and as little as $10-15 \%$ G type G-6-PD. With cellulose acetate electrophoresis, one could detect as little as 5-10\% of each G-6PD type. Since hemoglobin comigrates with G-6-PD on cellulose acetate, one cannot analyze erythrocyte preparations with this procedure.

The isoelectric focusing technique was sufficiently sensitive such that the G-6-PD type of individual bursts with 50-100 erythroblasts or GM colonies with more than 8 monocytes or 20 granulocytes could be reliably determined.

Demonstration that the structural locus of feline G-6-PD is on that part of the $X$-chromosome that is inactivated and that the ratio of G-6-PD activities remains stable. To demonstrate that feline G-6-PD is X-linked, blood cells from the hybrid offspring of a Geoffroy male and multiple female cats were examined. All $F_{1}$ females $(n=20)$ had both $d$ and $G$ banding. The five $F_{1}$ male cats tested had single $d$ bands, the maternal banding pattern. Of 1,557 hematopoietic colonies tested, 779 were $d$ and 758 were $G$. Both $d$ and $G$ bands were seen in 20 colonies (1.3\%). That the G-6-PD type of hematopoietic colonies was either $d$ or $\mathbf{G}$, but rarely both, demonstrates that only one G-6-PD locus was active in each BFU-E or CFU-GM and its differentiated progeny (Fig. 2). These observations also prove that feline hematopoietic colonies originate from a single precursor.

Table I shows the percentage of colonies containing d-type G-6-PD from $20 F_{1}$ heterozygotes. The mean is $50 \% \pm 11 \%$ (SD) and the median is $49 \%$. In each heterozygous cat tested, the ratio of G-6-PD enzyme types in erythroid bursts and GM colonies was similar to the ratios of d/G G-6-PD activities determined for erythrocytes $(n=10)$, platelets $(n=5)$, granulocytes $(n=19$; Table I), and mononuclear peripheral blood cells $(n=12)$. Three heterozygous cats have been studied repeatedly for over $1 \mathrm{yr}$ and the $\mathrm{d} / \mathrm{G}$ ratios in peripheral blood cells and hematopoietic colonies have remained unchanged. Fig. 3 shows colony data in one cat. In a killed control cat, balanced G-6-PD d and $G$ activities were detected in spleen and node. Diffuse bands with equivalent activity in $d$ and $G$ regions were seen with G-6-PD analysis of liver and muscle.

Natural history of FeLV-C/Sarma and KT infection. Two heterozygous cats were infected with FeLV-C/Sarma and one male $F_{1}$ received FeLV-KT. Progressive anemia with reticulocytopenia developed 9-21 wk after infection. Granulocyte and 


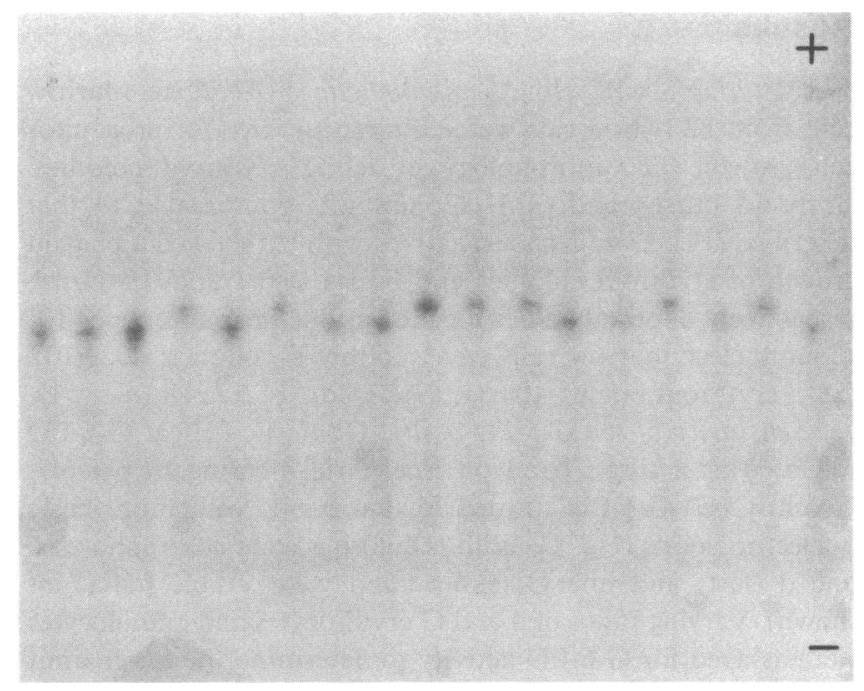

Figure 2. G-6-PD determination of individual GM colonies. GM colony lysates were placed near the cathode of a polyacrylamide gel. After isoelectric focusing and staining for G-6-PD, bands were visualized. This cat was a balanced heterozygote with similar numbers of more anodic (domestic or d) and more cathodic (Geoffroy or $\mathbf{G}$ ) bands. Colonies were either $\mathrm{d}$ or $\mathrm{G}$, not both, confirming $\mathrm{X}$-inactivation of feline G-6-PD. Similar results were obtained with erythroid bursts.

platelet counts remained normal. Bone marrow morphology was diagnostic of PRCA and showed erythroid aplasia, normal numbers and maturation of granulocyte precursors, and normal megakaryocytes. A few cells with deeply basophilic cytoplasm

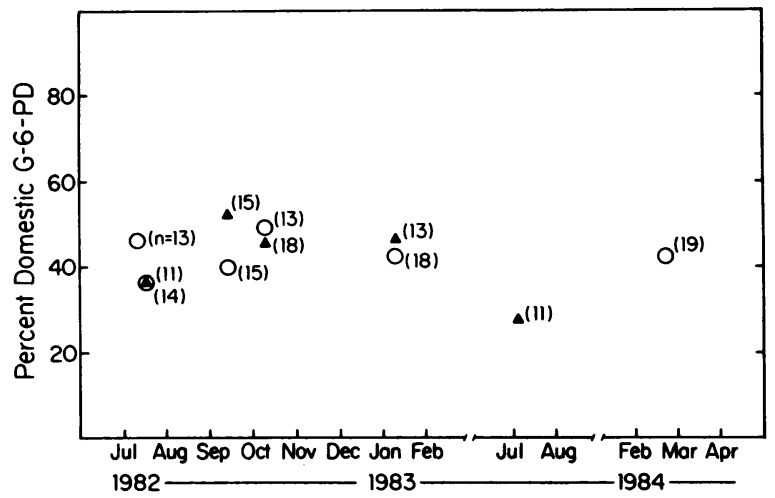

Figure 3. Percentage of colonies containing d-type enzymes in marrow cultures of a G-6-PD heterozygous cat (63133) studied longitudinally. $O$ represents GM colonies; $\Delta$, bursts, and $(n)$, the number of colonies analyzed for G-6-PD type each time. The percent of bursts with $d$ G-6-PD is similar to the percent of GM colonies with d G-6$P D$. The ratio of $d$ to $G$ type colony forming cells and peripheral blood granulocytes and erythrocytes remained stable during 18 mon of study.

characteristic of proerythroblasts were noted (Fig. 4). These cells did not stain with benzidine.

In cats infected with FeLV, viremia was detectable within 2-3 wk. All animals that remained persistently viremic developed PRCA. Of note, most cats developed transient cytopenias and a diarrheal illness $\sim 4-5$ wk after infection. Two cats died during this time, while two other cats cleared their FeLV infection and remained hematologically normal and virus negative by ELISA and immunofluorescence assays.

Table I. G-6-PD Type of Colonies and Granulocytes from Heterozygous Cats

\begin{tabular}{|c|c|c|c|c|c|c|c|c|c|}
\hline \multirow[t]{2}{*}{ Cat } & \multicolumn{3}{|c|}{ Bursts } & \multicolumn{3}{|c|}{ GM colonies } & \multicolumn{2}{|c|}{ Total colonies } & \multirow{2}{*}{$\begin{array}{l}\text { Granulocytes } \\
\begin{array}{l}\text { \%d Cellulose } \\
\text { acetate }\end{array}\end{array}$} \\
\hline & $d$ & $G$ & $\% d$ & $d$ & $G$ & $\% d$ & $\% d$ & $\begin{array}{l}95 \% \text { Confidence } \\
\text { limit }\end{array}$ & \\
\hline 63131 & 53 & 35 & 60 & 103 & 76 & 58 & 58 & \pm 6 & 50 \\
\hline 63132 & 60 & 19 & 76 & 57 & 37 & 61 & 68 & \pm 7 & 50 \\
\hline 63133 & 25 & 32 & 44 & 38 & 52 & 42 & 43 & \pm 8 & 40 \\
\hline 63134 & 19 & 39 & 33 & 32 & 59 & 35 & 34 & \pm 8 & 50 \\
\hline 63179 & 4 & 3 & 57 & 28 & 20 & 58 & 58 & \pm 14 & 60 \\
\hline 63689 & 13 & 15 & 46 & 19 & 14 & 58 & 52 & \pm 13 & 40 \\
\hline 63690 & 20 & 16 & 56 & 24 & 19 & 56 & 56 & \pm 12 & 50 \\
\hline 63691 & 28 & 52 & 35 & 35 & 46 & 43 & 39 & \pm 8 & 50 \\
\hline 63775 & 8 & 13 & 38 & 11 & 18 & 38 & 38 & \pm 14 & 40 \\
\hline 63776 & 3 & 9 & 25 & 14 & 18 & 44 & 39 & \pm 16 & 40 \\
\hline 63846 & 11 & 10 & 52 & 8 & 27 & 23 & 34 & \pm 13 & 40 \\
\hline 63848 & 5 & 5 & 50 & 16 & 10 & 62 & 58 & \pm 18 & 60 \\
\hline 63851 & 10 & 16 & 38 & 16 & 17 & 48 & 44 & \pm 13 & 50 \\
\hline 64013 & 9 & 13 & 41 & 17 & 15 & 53 & 48 & \pm 14 & - \\
\hline 64029 & 13 & 14 & 48 & 13 & 17 & 43 & 46 & \pm 14 & 40 \\
\hline 64030 & 6 & 3 & 67 & 19 & 15 & 56 & 58 & \pm 16 & 50 \\
\hline 64031 & 17 & 5 & 77 & 17 & 17 & 50 & 61 & \pm 14 & 50 \\
\hline 64146 & 3 & 7 & 30 & 12 & 12 & 50 & 44 & \pm 18 & 50 \\
\hline 64147 & 4 & 8 & 33 & 17 & 13 & 57 & 50 & \pm 16 & 50 \\
\hline 64337 & 1 & 1 & 50 & 12 & 4 & 75 & 72 & \pm 24 & 50 \\
\hline Mean & & & 48 & & & 51 & 50 & & \\
\hline
\end{tabular}




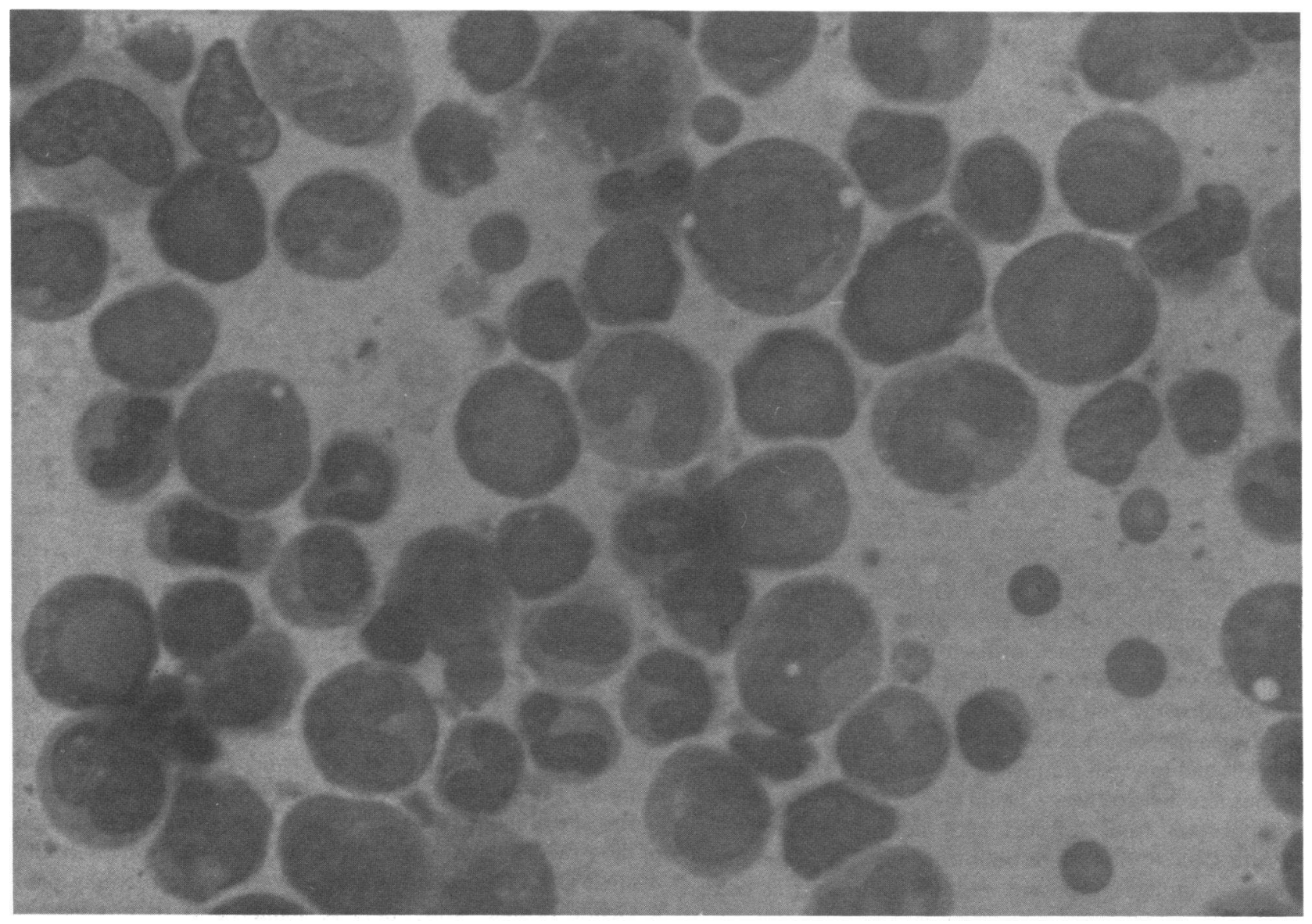

Figure 4. Marrow aspirate from cat \#63775 with PRCA stained with Wright-Giemsa $(\times 100)$. Several cells with dark cytoplasm characteristic of proerythroblasts are seen.

The results of assays for colony-forming units in three cats that developed PRCA are shown in Fig. 5. At a time when the hematocrit was decreased, CFU-E-derived colonies were undetectable, although virtually normal numbers of BFU-Eand CFU-GM-derived colonies were found. Similar results were obtained in an adolescent domestic cat given FeLV-C/
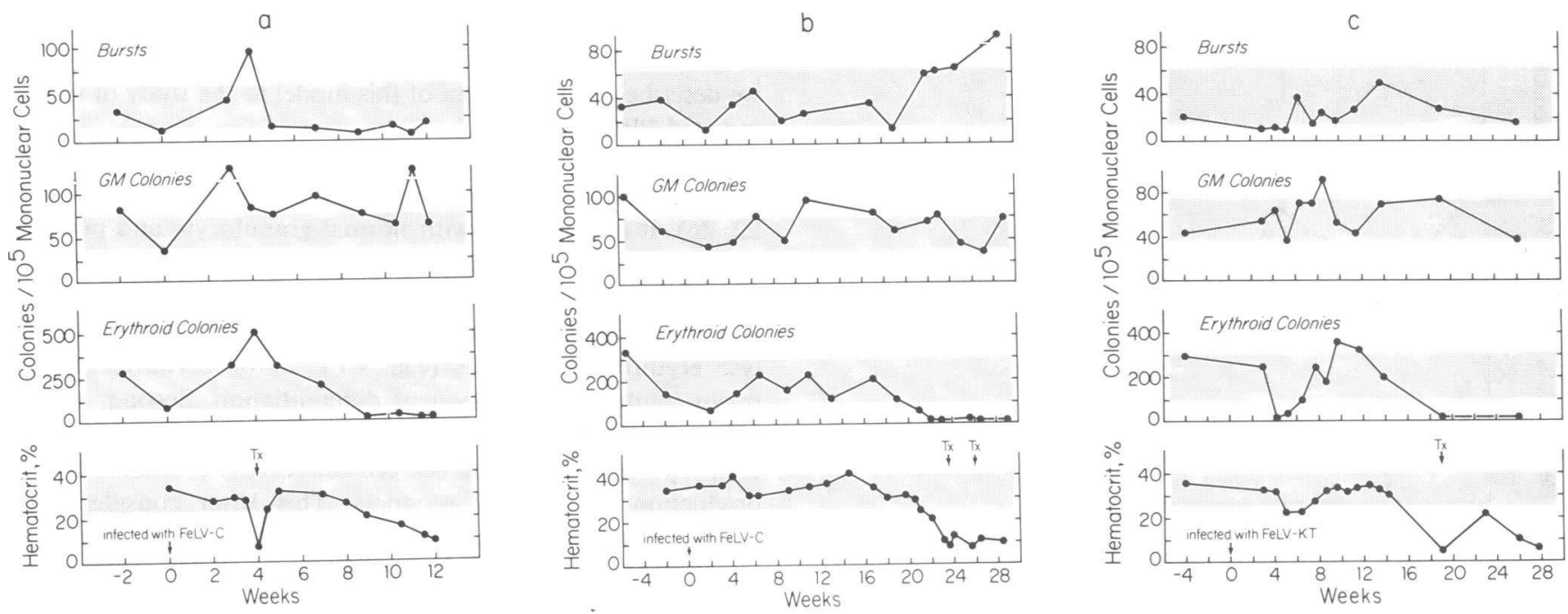

Figure 5. Experimentally induced PRCA in hybrid cats. Individual points represent the mean colony counts of three identical methylcellulose plates with $10^{5}$ mononuclear marrow cells. $0.5 \mathrm{U} / \mathrm{ml} \mathrm{Ep}$ was used in all cultures. Tx indicates transfusions. In each cat studied, erythroid colonies became undetectable in vitro coincidentally with the fall in hematocrit. Normal numbers of erythroid bursts persisted. (a) cat 63775, $F_{1}$ female infected with FeLV-C/Sarma, (b) cat 63776, $F_{1}$ female infected with FeLV-C/Sarma, $(c)$ cat $63530, F_{1}$ male infected with FeLV-KT. 
Sarma to induce PRCA (Fig. 6). In this domestic cat, however, the number of BFU-E detectable in culture decreased late in its disease course.

At postmortem examination, thymic atrophy and mild diffuse adenopathy were evident. Histopathology demonstrated marrow hypocellularity, depletion of cells in the paracortical and cortical regions of lymph nodes, and less developed follicles in the spleen. The causes of death, feline infectious peritonitis (cat 63530) and nonbacterial pneumonitis (cat 63775), were consistent with immunologic suppression induced by FeLV $(3,25)$. The third hybrid cat $(63776)$ was killed when anemic $(\mathrm{Hct}=10)$ and while clinically healthy. Except for mild atrophy of villi and hyperplasia of the crypt epithelium in the small bowel, nonhematopoietic tissues from this cat were normal.

G-6-PD determinations in $F_{1}$ heterozygous cats with $P R C A$. The G-6-PD types of erythroid bursts and GM colonies obtained from the two heterozygous cats with PRCA are shown in Table II. Both cats remained balanced heterozygotes throughout the study. Variations in $d / G$ ratios are not statistically significant $(P>0.4)$ and most likely reflect the small numbers of colonies examined at each data point. Ratios of G-6-PD d and G activities in serial preparations of erythrocytes, platelets, granulocytes, and peripheral blood mononuclear cells ranged between 40:60 and 50:50.

ER+ cells and mitogen-stimulated nonadherent lymphocyte preparations also showed nearly equal G-6-PD activities. However, lymphocytes from infected cats did not numerically expand with Con A. Therefore, following the 3-d adherence procedure and mitogen exposure, residual cells were at best 95\% lymphocytes by morphologic criteria.

Postmortem specimens were obtained from one cat (63776) for G-6-PD study. Balanced activity of $d$ and $G$ were seen in spleen, spleen mononuclear cells, lymph nodes, liver and muscle.

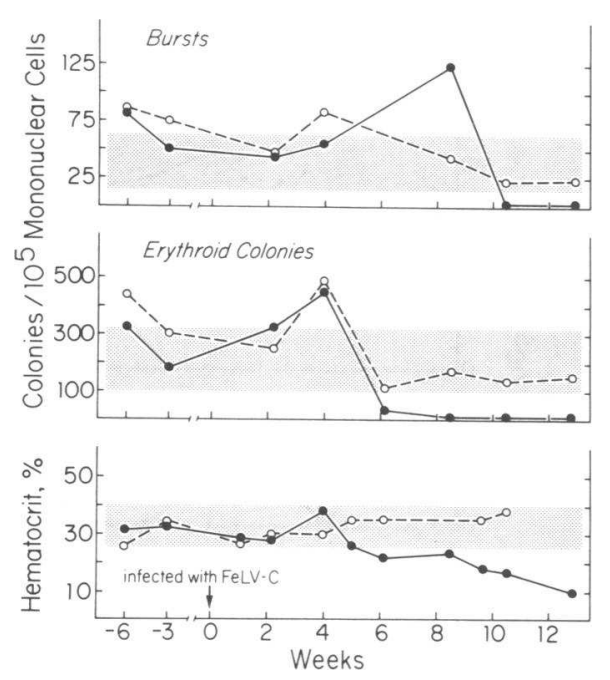

Figure 6. Experimentally induced PRCA in an adolescent domestic cat $(\bullet)$. Colony growth and hematologic parameters were compared with a littermate control (o). When the hematocrit began to fall, erythroid colonies became undetectable though erythroid bursts were present. Later in this cat's disease course, however, erythroid bursts were not seen
Table II. G-6-PD Analysis of Hematopoietic Precursors in Heterozygous Cats with PRCA

\begin{tabular}{lll}
\hline Week & BFU-E & CFU-GM \\
\hline & $\% d$ & $\% d$
\end{tabular}

\begin{tabular}{|c|c|c|c|}
\hline \multicolumn{4}{|l|}{ Cat 63775} \\
\hline $\begin{array}{l}\text { Baseline } \\
\text { (Hct 33) }\end{array}$ & $-2-0$ & $38(n=21)$ & $38(n=29)$ \\
\hline $\begin{array}{l}\text { Anemic } \\
\text { (Hct 10-21) }\end{array}$ & $9-12$ & $50(n=2)$ & $32(n=50)$ \\
\hline Cat 63776 & & & \\
\hline $\begin{array}{l}\text { Baseline } \\
\text { (Hct 37) }\end{array}$ & $-6-0$ & $25(n=12)$ & $44(n=32)$ \\
\hline $\begin{array}{l}\text { Anemic } \\
\text { (Hct 7-20) }\end{array}$ & $22-29$ & $44(n=27)$ & $49(n=47)$ \\
\hline
\end{tabular}

$n$, Number of individual colonies tested.

\section{Discussion}

To prospectively analyze the cellular events that precede overt neoplasia, we have developed a model of cellular mosaicism in the cat. The South American wildcat ( $L$. geoffroyi) and domestic cat ( $F$. catus), species that have evolved independently during the millions of years following the geographic separation of the American and Asian continents, have electrophoretically distinct G-6-PD enzyme patterns. We have successfully bred a Geoffroy male with domestic female cats to produce $F_{1}$ females, which are obligate G-6-PD heterozygotes. We have confirmed that the structural locus for feline G-6-PD is Xlinked and extended this observation to demonstrate that it undergoes random inactivation. We have shown that hematopoietic colonies growing in cultures have a single-cell origin and that somatic cells from G-6-PD heterozygous cats have balanced ratios of domestic and Geoffroy enzymes that are stable over time. The model can thus be applied to many issues concerning clonal evolution in neoplasia and, for example, to the study of FeLV-induced disease. In this report, we describe the application of this model to the study of virusinduced PRCA.

Experimental infection with FeLV-C or KT causes PRCA in neonatal kittens and immune suppressed adult cats $(16,17$, $22,26)$. It is associated with normal granulocyte and platelet counts and, in some animals, myelofibrosis (22). Although the mechanism by which erythropoiesis is inhibited is not clear, several possibilities are apparent. First, virus might infect and lyse erythroid stem cells (e.g., CFU-E) or erythroblasts or might inhibit their subsequent differentiation. Second, virusinfected accessory cells (e.g., lymphocytes) might interfere with erythropoiesis directly via cell-cell interaction or indirectly via production of humoral products. This latter consideration would be consistent with the tropism of this retrovirus for lymphocytes and postulated mechanisms of PRCA in man (27-29). In addition, infection with FeLV might result in the clonal proliferation of a hematopoietic stem cell that has lost its capacity for erythroid differentiation. Consistent with this, human PRCA has been found as a preleukemic illness and as a manifestation of myelodysplastic syndromes (30). Recent 
studies of a G-6-PD heterozygous patient with pancytopenia confirm that marrow failure may result from the clonal expansion of the myeloid stem cell (8). Alternatively, an infected and transformed accessory cell might clonally expand. Retroviruses cause clonal lymphomas in cats (31), birds (32), mice (33), rats (34), and man (HTLV) (35) as demonstrated by hybridization probes to viral and flanking sequences following restriction endonuclease digestion of tumor DNA. In addition, clonal lymphoid malignancies in man such as chronic lymphocytic leukemia and thymoma, have been associated with PRCA (27).

To investigate the possible role of clonal expansion in the pathogenesis of PRCA we analyzed the enzyme type of cells from G-6-PD heterozygous cats with FeLV-C-induced disease. If feline PRCA were a clonal disorder of the myeloid stem cell, we would predict that in granulocytes, platelets, erythrocytes, BFU-E and CFU-GM either $d$ or G type G-6-PD would predominate over time. In contrast, if PRCA were caused by a humoral or cellular suppression of erythroid progenitors, both G-6-PD types would be found among myeloid cells.

In two cats studied longitudinally, no significant change was seen in the ratio of $\mathbf{d}$ to $\mathrm{G}$ G-6-PD activities in blood cells or in erythroid bursts or GM colonies. PRCA in the cat is thus not a clonal disease of a myeloid stem cell. Although no change was seen in the $d$ to $G$ G-6-PD ratios in lymphocyte preparations, we cannot exclude the possibility that FeLV infection resulted in the expansion of a clone of $T$ or $B$ lymphocytes. As reported by others (36), lymphocytes from our cats infected with FeLV did not proliferate with Con A. Preparations of mononuclear cells exposed to mitogen during a 3-d adherence procedure were, at best, 95\% lymphocytes by morphologic criteria and presumably contained both $\mathrm{T}$ and $\mathrm{B}$ cells. Preparations of ER+ mononuclear cells contained some monocytes. As the G-6-PD activity per lymphocyte is $1 / 10-1$ / 20 that of a monocyte or granulocyte, results suggesting balanced activity in the lymphocyte population are difficult to interpret.

In addition to determining whether feline PRCA is a clonal disease, we analyzed the effect of in vivo FeLV infection on the number of hematopoietic progenitors. As cats developed anemia, CFU-E were no longer detected in marrow cell culture. However, essentially normal numbers of erythroid bursts remained in three $F_{1}$ hybrid cats and one domestic cat with experimentally induced PRCA. These data suggest that erythropoiesis is inhibited in vivo subsequent to the BFU-E. That BFU-E are able to differentiate to erythroid bursts in vitro implies that the in vivo inhibition is potentially reversible. Inhibition at the CFU-E or proerythroblast level of differentiation would be consistent with the morphology of marrow aspirates that suggests persisting proerythroblasts. As feline CFU-E are detectable as well-hemoglobinized colonies by day 3 in culture, it is likely that there are few cell divisions between CFU-E and erythroblasts in cats. This implies that CFU-E may not be expressed in vitro as recognizable erythroid colonies if the hemoglobinization of developing proerythroblasts were impaired.

Our observations contrast the results of other groups. In studies by Onions et al. (16) and Testa et al. (17), the number of BFU-E detected in marrow cultures from neonatal cats decreased 2-3 wk following infection with FeLV-C/Sarma and the hematocrit decreased at 6-7 wk. Similar results were obtained by Gasper et al. (26) in studies of PRCA in steroidsuppressed adolescent domestic cats infected with FeLV-KT. These authors postulated a direct effect of virus on early erythroid progenitors that resulted in a decline in subsequent erythropoiesis and produced severe anemia. The reasons for the differences between our results and those previously reported are presently unknown.

More importantly, however, we have described an experimental system in which issues such as clonal dominance in neoplasia and the influence of virus on hematopoietic precursor number and differentiation may be addressed. As the G-6-PD type of a cell is not related to a viral disease process or transforming event, but is fixed in embryogenesis, the analysis of G-6-PD type independently evaluates clonal evolution. Hybrid cats become viremic with FeLV and develop clinical disease similar to naturally and experimentally infected domestic cats. G-6-PD heterozygous animals may be studied repeatedly over time so that each animal serves as its own control. As an initial application of this model of G-6-PD cellular mosaicism, we have shown that FeLV-induced PRCA does not result from the clonal expansion of an abnormal myeloid stem cell. This model should be applicable to the study of clonal evolution in vivo and the interactions of normal and neoplastic cells in vitro in other experimental disease states.

\section{Acknowledgments}

The authors would like to thank Dr. Edward Hoover, College of Veterinary Medicine and Biological Sciences, Colorado State University, Fort Collins, CO, for quantitating the viral inocula, Dr. Ellis Giddens, Department of Animal Medicine, University of Washington, for performing the autopsies and preparation of histologic specimens, Richard Holly for excellent technical help, and Cindy Reid for preparation of the manuscript.

This work was supported by grants AM19410, AM23130, GM15253 and HL31823 from the National Institutes of Health, Department of Health and Human Services.

\section{References}

1. Fialkow, P. J. 1976. Clonal origin of human tumors. Biochim. Biophys. Acta. 458:283-321.

2. Hardy, Jr., W. D., P. W. Hess, E. G. MacEwen, A. J. McClelland, E. E. Zuckerman, M. Essex, S. M. Cotter, and O. Jarrett. 1976. Biology of feline leukemia virus in the natural environment. Cancer Res. 36:582-588.

3. Hardy, W. D. 1980. Feline leukemia virus diseases. In: Feline Leukemia Virus, W. D. Hardy, Jr., M. Essex, and A. J. McClelland, editors. Elsevier/North Holland, New York. pp. 3-33.

4. Maggio, L., R. Hoffman, S. M. Cotter, N. Dainiak, S. Mooney, and L. A. Maffei. 1978. Feline preleukemia: an animal model of human disease. Yale J. Biol. Med. 51:469-476.

5. Fialkow, P. J. 1980. Clonal and stem cell origin of blood cell neoplasms. In: Contemporary Hematology/Oncology, J. Lobue, A. S. Gordon, R. Silber, and F. M. Muggia, editors. Plenum Press, New York. pp. 1-46.

6. Jacobson, R. J., W. Raskind, R. A. Sacher, G. Shashaty, J. W. Singer, and P. J. Fialkow. 1983. Refractory anemia (RA), a myelodysplastic syndrome: clonal development with progressive loss of normal committed progenitors. Blood. 60(Suppl. 1):129a. (Abstr.)

7. Fialkow, P. J., J. W. Singer, J. W. Adamson, K. Vaidya, L. W. Dow, J. Ochs, and J. W. Moohr. 1981. Acute nonlymphocytic leukemia: heterogeneity of stem cell origin. Blood. 57:1068-1073. 
8. Abkowitz, J. L., P. J. Fialkow, D. J. Niebrugge, W. H. Raskind, and J. W. Adamson. 1984. Pancytopenia as a clonal disorder of a multipotent hematopoietic stem cell. J. Clin. Invest. 73:258-261.

9. Nielsen, J. T., and V. W. Chapman. 1977. Electrophoretic variation for X-chromosome-linked phosphoglycerate kinase (PGK-1) in the mouse. Genetics. 87:319-325.

10. Reddy, A. L., and P. J. Fialkow. 1983. Clonal development of lymphomas induced by Rauscher leukemia virus. Int. J. Cancer. 31:107-109.

11. Collins, S. J., and P. J. Fialkow. 1983. Clonal nature of mink cell focus-inducing virus-induced AKR leukemia: studies with Xchromosome inactivation cellular mosaicism. J. Natl. Cancer Inst. 70:529-533.

12. Ohno, S., J. Poole, and I. Gustavsson. 1965. Sex-linkage of erythrocyte glucose-6-phosphate dehydrogenase in two species of wild hares. Science (Wash. DC). 150:1737-1738.

13. Lee, K. T., W. A. Thomas, K. Janakidevi, M. Kroms, J. M. Reiner, and K. Y. Borg. 1981. Mosaicism in female hybrid hares heterozygous for glucose-6-phosphate dehydrogenase (G-6-PD). 1. General properties of a hybrid hare model with special reference to atherogenesis. Exp. Mol. Pathol. 34:191-201.

14. Warren, P. N., and R. Riedel. 1980. Preliminary results of hybridizing Leopardus geoffroyi and Felis catus. Carnivore Genet. 4:108-121.

15. O'Brien, S. J., and W. G. Nash. 1982. Genetic mapping of mammals: chromosome map of domestic cat. Science (Wash. DC). 216:257-265.

16. Onions, D., O. Jarrett, N. Testa, F. Frassoni, and S. Toth 1982. Selective effect of feline leukaemia virus on early erythroid precursors. Nature (Lond.). 296:156-158.

17. Testa, N. G., D. Onions, O. Jarrett, F. Frassoni, and J. F. Eliason. 1983. Haemopoietic colony formation (BFU-E, GM-CFC) during the development of pure red cell hypoplasia induced in the cat by feline leukaemia virus. Leukaemia Res. 7:103-116.

18. Singer, J. W., J. W. Adamson, C. Ernst, N. Lin, L. Steinmann, S. Murphy, and P. J. Fialkow. 1980. Polycythemia vera. Physical separation of normal and neoplastic committed granulocyte-macrophage progenitors. J. Clin. Invest. 66:730-735.

19. Taylor, D., Y. Hokama, and S. F. Perri. 1975. Differentiating feline T and B lymphocytes by rosette formation. J. Immunol. 115:862 865.

20. Sparkes, R. S., M. C. Baluda, and D. E. Townsend. 1969. Cellulose acetate electrophoresis of human glucose-6-phosphate dehydrogenase. J. Lab. Clin. Med. 73:531-534.

21. Sarma, P. S., and T. Log. 1973. Subgroup classification of feline leukemia and sarcoma viruses by viral interference and neutralization tests. Virology. 54:160-169.

22. Hoover, E. A., G. J. Kociba, W. D. Hardy, Jr., and D. S.
Yohn. 1974. Erythroid hypoplasia in cats inoculated with feline leukemia virus. J. Natl. Cancer Inst. 53:1271-1276.

23. Fischinger, P. J., C. S. Blevins, and S. Nomura. 1974. Simple, quantitative assay for both xenotropic murine leukemia and ecotropic feline leukemia viruses. $J$. Virol. 14:177-179.

24. Hoover, E. A., R. G. Olsen, L. E. Mathes, and J. P. Schaller. 1977. Relationship between feline leukemia virus antigen expression and viral infectivity in blood, bone marrow and saliva of cats. Cancer Res. 37:3707-3710.

25. Trainin, Z., D. Wernicke, H. Ungar-Waron, and M. Essex. 1983. Suppression of the humoral antibody response in natural retrovirus infections. Science (Wash. DC). 220:858-859.

26. Gasper, P. W., and E. A. Hoover. 1983. Feline leukemia virus strain specific abatement of erythroid burst forming units (BFU-E). Leukemia Rev. Int. 1:71-72. (Abstr.)

27. Krantz, S. B., and S. D. Zaentz. 1977. Pure red cell aplasia. The Year in Hematology. A. S. Gordon, R. Silber, and J. LoBue, editors. Plenum Medical Book Co., New York. 153-190.

28. Nagasawa, T., T. Abe, and T. Nakagawa. 1981. Pure red cell aplasia and hypogammaglobulinemia associated with T-cell chronic lymphocytic leukemia. Blood. 57:1025-1031.

29. Levitt, L., D. Moonka, E. Englemann, and C. Cabradilla. 1983. HTLV-associated T-suppressor cell inhibition of erythropoiesis in a patient with pure red cell aplasia (PRCA) and hypogammaglobulinemia (H). Blood. 62(Suppl. 1):48a. (Abstr.)

30. Clark, D. A., E. N. Dessypris, and S. B. Krantz. 1984. Studies on pure red cell aplasia. XI. Results of immunosuppressive treatment of 37 patients. Blood. 63:277-286.

31. Neil, J. C., D. Hughes, R. McFarlane, N. M. Wilkie, D. E. Onions, E. Lees, and O. Jarrett. 1984. Transduction and rearrangement of the $m y c$ gene by feline leukaemia virus in naturally occurring Tcell leukaemias. Nature (Lond.). 308:814-820.

32. Neel, B. G., W. S. Hayward, H. L. Robinson, J. Fang, and S. M. Astrin. 1981. Avian leukosis virus-induced tumors have common proviral integration sites and synthesize discrete new RNAs: oncogenesis by promotor insertion. Cell. 23:323-334.

33. Steffen, D., and R. A. Weinberg. 1978. The integrated genome of murine leukemia virus. Cell. 15:1003-1010.

34. Tsichlis, P. N., P. G. Strauss, and L. F. Hu. 1983. A common region for proviral DNA integration in MoMuLV-induced rat thymic lymphomas. Nature (Lond.). 302:445-449.

35. Wong-Staal, F., B. Hahn, V. Manzari, S. Colombini, G. Franchini, E. P. Gelmann, and R. C. Gallo. 1983. A survey of human leukaemias for sequences of human retrovirus. Nature (Lond.). 302:626628.

36. Cockerell, G. L., E. A. Hoover, S. Krakowka, R. G. Olsen, and D. S. Yohn. 1976. Lymphocyte mitogen reactivity and enumeration of circulating B- and T-cells during feline leukemia virus infection in the cat. J. Natl. Cancer Inst. 57:1095-1099. 